\title{
The Right Renal Vein Extension: Technical Review
}

\section{Tamayo Enriquez G*, Burdine LJ, Giorgakis E and Barone GW \\ University of Arkansas for Medical Sciences, Division of Transplant Surgery, USA}

*Corresponding author: Gerardo Tamayo-Enriquez, University of Arkansas for Medical Sciences, Division of Transplant Surgery, Little Rock, Arkansas, USA, Tel: +1(501)526-6262; Email: gtamayoenriquez@uams.edu

\section{Mini Review}

Volume 3 Special Issue 1

Received Date: December 19, 2018

Published Date: January 11, 2019

DOI: $10.23880 / \mathrm{ijtps}-16000 \mathrm{~S} 1-001$

\section{Abstract}

Transplantation of the right kidney from cadaveric donors is more technically challenging than transplantation of the left kidney due to the shorter length of the right renal vein. Several techniques have been used to extend the right renal vein, but the paucity of data to guide evidence-based decisions mandates that the surgeon must approach each transplant on a case-by-case basis. It is generally agreed that extension of the right renal vein allows for an easier implantation. This paper provides a brief review of several techniques for right renal vein extension in deceased donors.

Keywords: Right renal vein; Extension; Kidney transplant; Surgical technique

\section{Introduction}

The left renal vein (LRV) is on average 3-4 cm longer than the right renal vein (RRV), thus making it more suitable for transplantation. In an anatomical study of 119 cadavers, the RRV varied from 21 to $71 \mathrm{~mm}$ and the right renal artery varied from 44 to $111 \mathrm{~mm}$, [1] but generally surgeons prefer to have both vessels of a similar length. Several techniques have been described in the literature for extending the RRV in deceased and living donor kidney transplantation. Although the outcomes of right versus left are usually the same, there is a discrepancy in early graft complications when the RRV is used with or without extension. It is important for the transplant surgeon to be familiar with several techniques of RRV extension in deceased donors. This paper seeks to explore some of the techniques described in the literature for RRV extension in deceased donors and techniques used at the kidney transplant program at the University of Arkansas for Medical Sciences.
One of the early studies, performed in 1994 at the University of Minnesota, analyzed 305 cadaveric transplant recipients receiving a right kidney; no early vascular complications were noted when an extension was used versus $2.2 \%$ without. This same study found no difference in 1 and 2 year graft survival rates with or without extension [2]. Barry and Fuchs described a surgical technique using the inferior vena cava (IVC) in 1978 that relies on suturing the upper and lower ends of an IVC conduit [3]. The use of non-absorbable suture for elongation of the IVC patch has been shown to be safe and effective in decreasing warm ischemia time and improving exposure [4]. with the advent of reusable vascular stapling devices, hand suturing is now replaced by lines of staples. Stapling in this way is a safe option and can increase the RRV by 3-5 centimeters [5]. Dalla Valle, et al. found no difference in thrombosis, delayed graft function, or graft loss in 371 right kidney transplant recipients whether an extension was used or not; however, there was a reduction in mean warm ischemic time from 56 to 49 minutes [6]. To facilitate the 


\section{International Journal of Transplantation \& Plastic Surgery}

reconstruction, a 3-4 mm cuff of IVC should be left while separating the LRV at time of procurement [7]. Despite evidence correlating use of right kidneys and vascular thrombosis [8], other series could not identify laterality as a risk factor $[9,10]$. A retrospective cohort study from the Netherlands analyzed 4,372 living and 5,346 deceased donor kidney transplants and found the use of right kidneys increased the incidence of technical graft failure only when using living donors (multivariate analysis $\mathrm{p}=0.03)$ [11].

\section{Techniques}

Figures 1 to 6 demonstrate several extension techniques using a human cadaveric right kidney not suitable for transplantation (obtained with permission from the local Organ Procurement Organization for research). All reconstructions were performed under $3.5 \mathrm{x}$ magnification using 7-0 non- absorbable suture and a 35 $\mathrm{mm}$ vascular stapler.

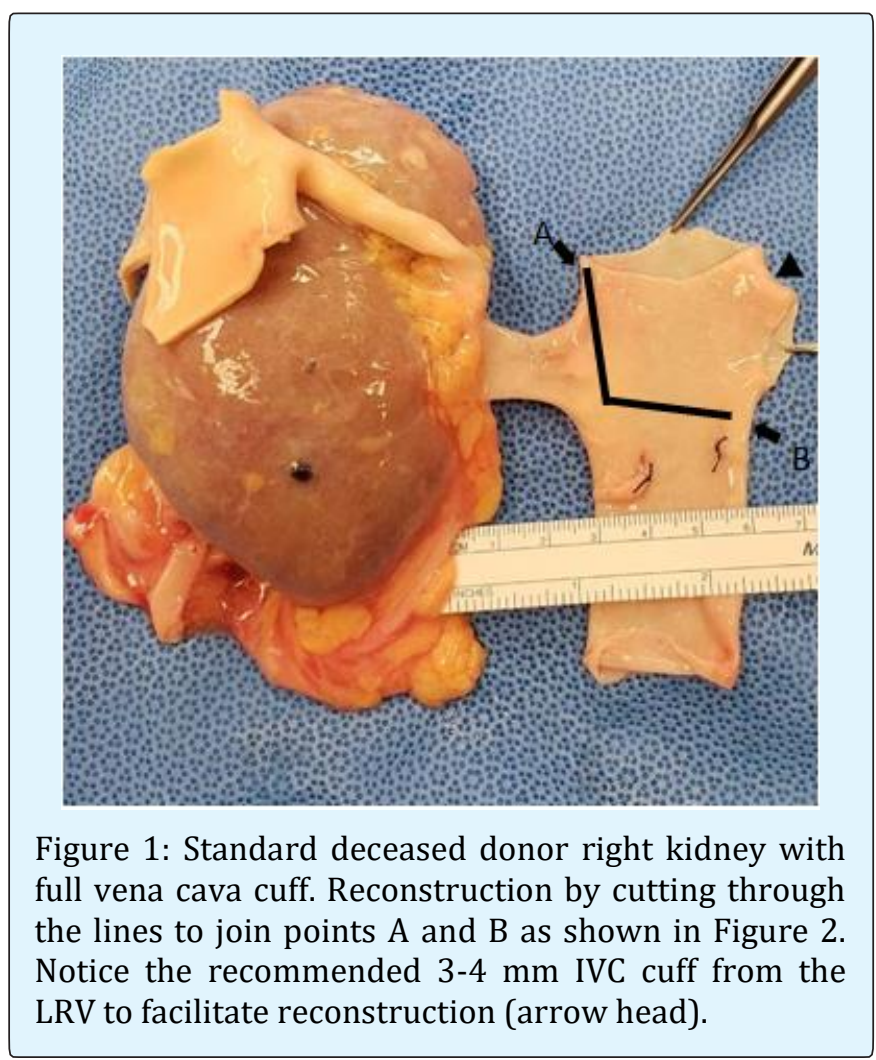

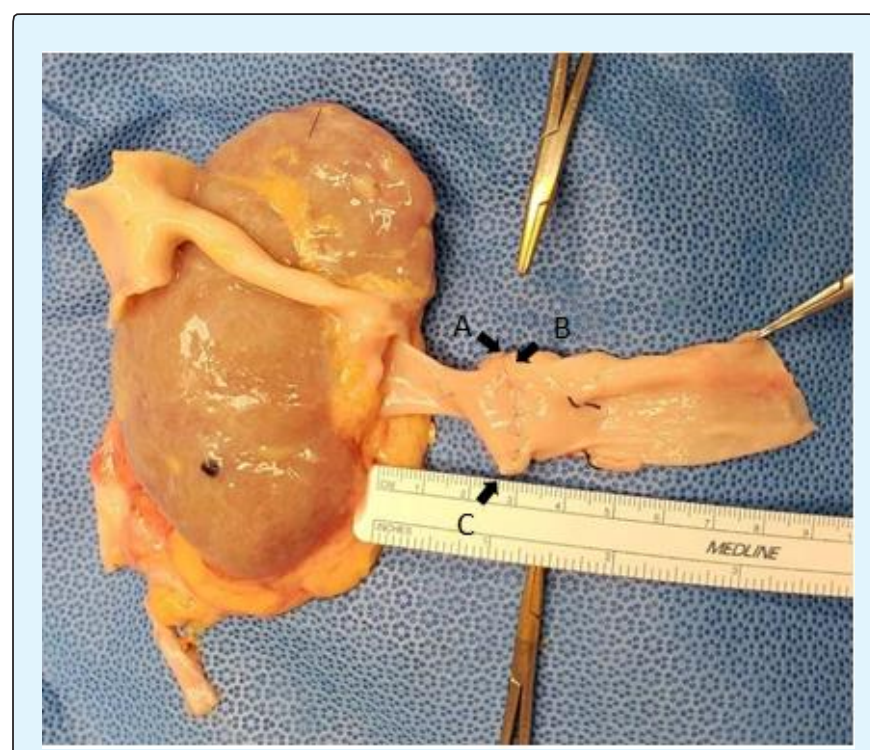

Figure 2: Anatomical extension using IVC cuff, point C can have so called "dog ears" that might need to be trimmed/repaired.

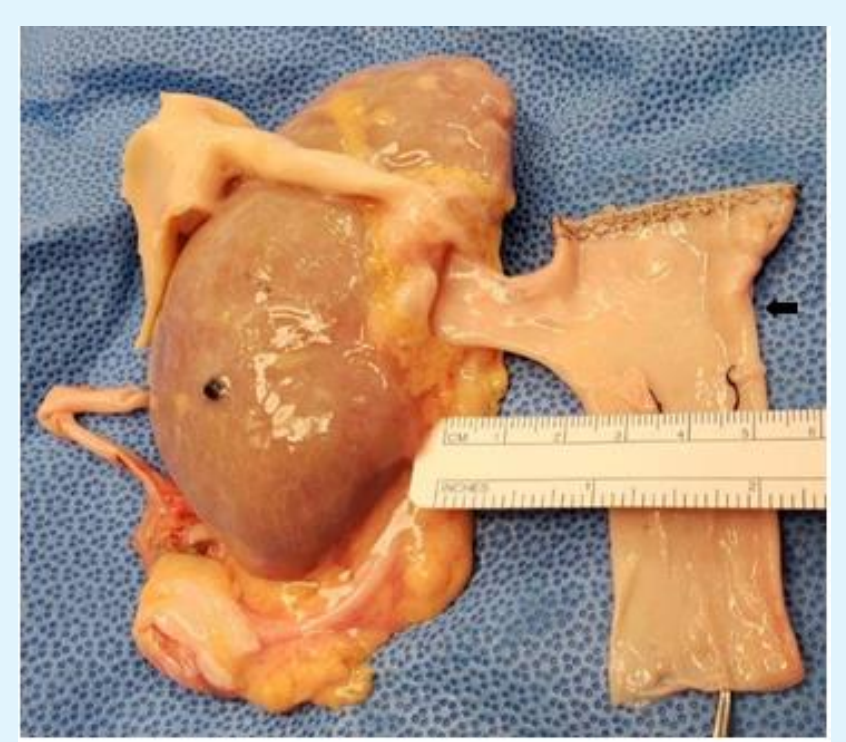

Figure 3: RRV reconstruction in a $\mathrm{T}$ configuration using vascular stapler and hand suturing of the ostium of the left renal vein (arrow) to preserve the full length of the IVC. 


\section{International Journal of Transplantation \& Plastic Surgery}
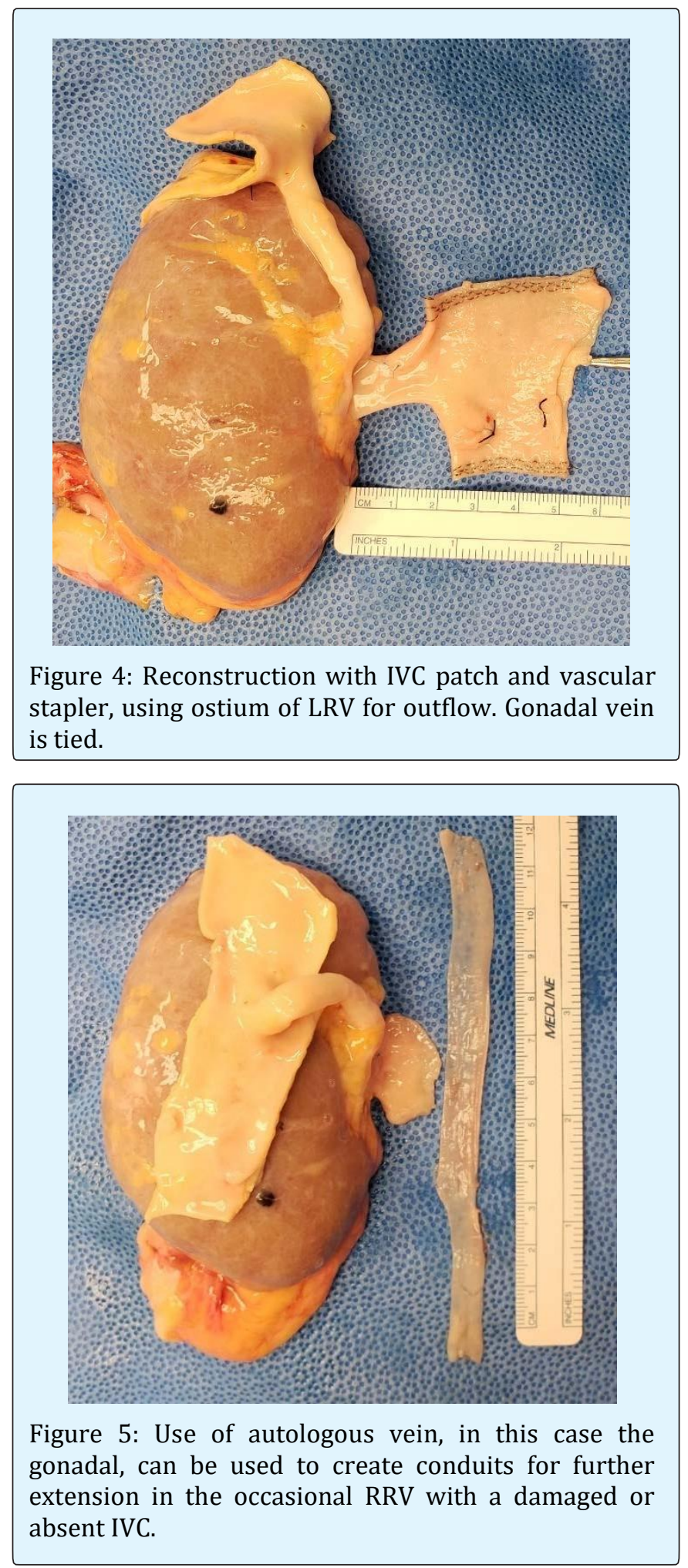

Tamayo Enriquez G, et al. The Right Renal Vein Extension: Technical Review. Int J Transplant \& Plastic Surg 2019, 3(S1): 000S1-001.

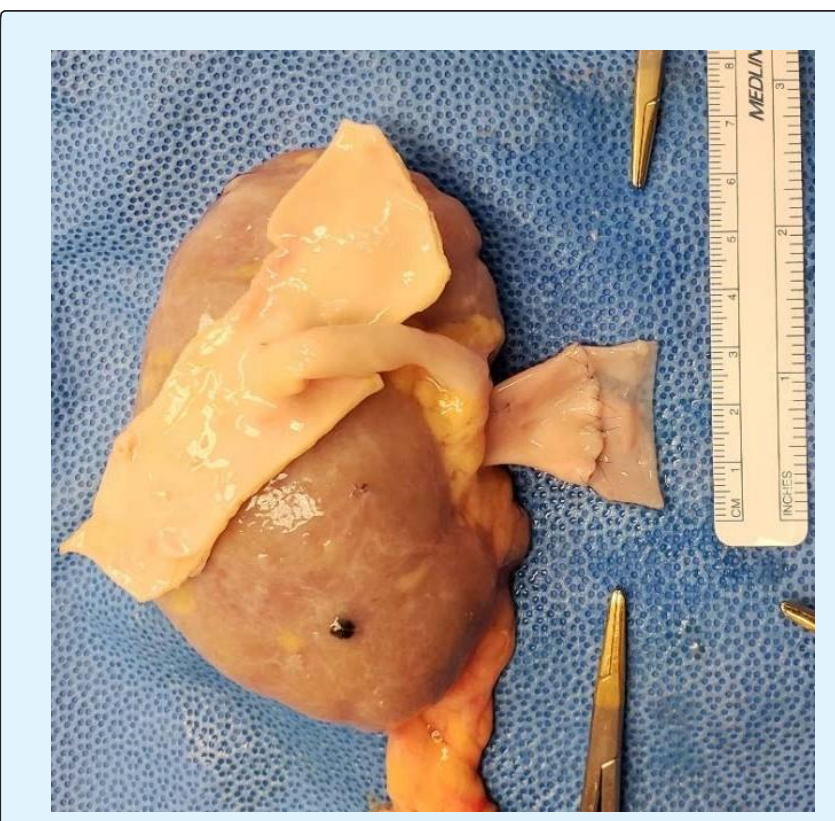

Figure 6: Autologous vein extension in place.

\section{Discussion}

Overall, the literature has shown mixed results for outcomes using left versus right kidneys from deceased donors. However, some data suggests the use of extensions in cadaveric right kidney transplants improve outcomes, decreases warm ischemic time, resulting in easier implantation. There are no studies regarding best choice of reconstruction, and a decision should be made on a case by case basis by the surgeon.

\section{References}

1. Janschek EC, Rothe AU, Hölzenbein TJ, Langer F, Brugger PC, et al. (2004) Anatomic basis of right renal vein extension for cadaveric kidney transplantation. Urology 63(4): 660-664.

2. Benedetti E, Fryer J, Matas AJ, Sutherland DE, Payne WD, et al. (1994) Kidney transplant outcome with and without right renal vein extension. Clin Transplant 8: 416-417.

3. Barry JM, Fuchs EF (1978) Right renal vein extension in cadaver kidney transplantation. Arch Surg 113(3): 300.

4. Gante MJ, Sánchez-Aguilar M, Tapia-Perez JH, Medina YT, Viñas-Rios JM, et al. (2015) Extension of right 


\section{International Journal of Transplantation \& Plastic Surgery}

renal vein in renal transplant from deceased donors: cohort study. Exp Clin Transplant 13(2): 126-129.

5. Fabian MA, Herrin MK, Baxter J, Ackermann JR (1991) Extension of the right renal vein in cadaveric renal transplants with use of the vena cava and the TA-30 V3 surgical stapler. Surg Gynecol Obstet 173(3): 233234.

6. DallaValle R, Mazzoni MP, Bignardi L, Busi N, Benozzi $\mathrm{L}$, et al. (2004) Renal vein extension in right kidney transplantation. Transplant Proc 36(3): 509-510.

7. Di Cocco Pierpaolo, Kandilis A, Rajagopal P, Herbert P, Hassen Y, et al. (2016) Surgical stapler for right renal vein elongation using the inferior vena cava in kidney transplant. Exp Clin Transplant 14(5): 564-566.
8. Bakir N, Sluiter WJ, Ploeg RJ, van Son WJ, Tegzess AM (1996) Primary renal graft thrombosis. Nephrology Dialysis Transplantation 11(1): 140-147.

9. de Freitas RAP, de Lima ML, Mazzali M (2017) Early vascular thrombosis after kidney transplantation: can we predict patients at risk?. Transplant Proc 49(4): 817-820.

10. Khan TT, Ahmad N, Siddique K, Fourtounas K (2018) Implantation of right kidneys: is the risk of technical graft loss real? World J Surg 42: 1536-1541.

11. Özdemir-van Brunschot DMD, van LaarHoven CJHM, van der Jagt MFP, Hoitsma AJ, Warlé MC (2016) Is the reluctance for the implantation of right donor kidneys justified? World J Surg 40(2): 471-478. 